\title{
Federación Latinoamericana de Sociedades de Obstetricia y Ginecología (FLASOG)
}

\author{
Av. Agraciada 1464-P. 13 - Montevineo, Uruguay. \\ Secretaría Permanente.
}

Montevideo, junio de 1953.

Señor Presidente de la Sociedad Colombiana de Obstetricia y Ginecolocía.

De nuestra consideración:

La Secretaría Permanente de la FLASOG tiene el agrado de comunicar a la institución de vuestra digna presidencia que, de acuerdo con el nombramiento efectuado por la Asamblea General realizada en el Primer Congreso Latinoamericano de Obstetricia y Ginecología, el Departamento de Ginecología y Obstetricia de la Associação Paulista de Medicina ha aceptado organizar el Segundo Congreso Latinoamericano de Obstetricia y Ginecología.

Conforme a la precedente informacićn y a las disposiciones estatutarias de la FLASOG, esta Secretaría Permanente convoca a vuestra institución para participar en el Segundo Congreso Latinoamericano de Obstetricia y Ginecología que se realizará en la ciudad de San Pablo, Brasil, desde el día 9 al 14 de julio de 1954 para tratar el siguiente temario:

\section{OBSTETRICIA}

a) Fisiopatología de la contracción uterina y sus aplicaciones en la clínica.

b) Estado actual de la hormonología placentaria.

\section{GINECOLOGIA}

a) Cirugía conservadora en ginecología. Sus bases fisiológicas y sus resultados.

b) Estudio crítico de los antibióticos en ginecología.

Dichos temas serán desarrollados en forma de Relatos, por los relatores of iciales designados por la institución organizadora del Congreso; Correlatos, por los correlatores que serán nombrados para cada tema por cada una de las socie. 
dades integrantes de la FLASOG; discusión y Contribuciones a los temas oficiales, en la forma habitual.

No habrá "temas libres".

Vuestra Sociedad deberá nombrar un correlator para cada tema, cuya nómina agradeceremos nos sea comunicada a la mayor brevedad posible.

El plazo para la recepción de los trabajos de Relatos Oficiales y Correlatos, ha sido fijado por la institución organizadora hasta el día 28 de febrero de 1954 . y deben ser dirigidos al Vicepresidente de la Comisión Organizadora del Segundo Congreso Latinoamericano y IV Congreso Brasileiro de Obstetricia y Ginecología, Dr. W. Souza Rudge. Dirección: Av. Brigadeiro Luiz Antonio, 278, 89. Andar. São Paulo. Brasil.

Al convocar a la Sociedad de vuestra digna presidencia para el Segundo Congreso Latinoamericano de Obstetricia y Ginecología, esta Secretaría Permanente agradece la debida atención a este comunicado, la pronta designación de los correlatores correspondientes a los temas fijados, y el dar la mayor difusión en las publicaciones médicas de vuestro país a las noticias relativas a este cortamen. saludos.

Reciba usted y demás directivos de vuestra Sociedad nuestros más atentos

Por la Secretaría Permanente de la FLASOG,

J. Alberto Castro.

$* * *$

Montevideo, julio 20 de 1953.

Señor Presidente de la Sociedad Colombiana de Orstetricia y Ginecología.

De nuestra consideración:

Cúmpleme reiterar a la institución de su digna presidencia la convocatoria para el Segundo Congreso Latinoamericano de Obstetricia y Ginecología, que se realizará en la ciudad de San Pablo, Brasil, desde el día 9 al 14 de julio de 1954, cuyo duplicado del texto respectivo se adjunta. A la vez tenemos el agrado de comunicar que la reglamentación de los correlatos estará regida por las siguientes normas:

a) Los correlatores se referirán exclusivamente a la experiencia personal o local sobre el tema, con exclusión de los aspectos generales y de los enfoques con propósitos exhaustivos.

b) Dispondrán de doce minutos, improrrogables, para su exposición.

c) La extensión del correlato para su publicación, no deberá exceder de ocho páginas de 20 por 28 centímetros, dactilografiadas a dos espacios.

1) El texto deberá ser enviado a la Comisión Organizadora y será admitido hasta el día 28 de febrero de 1954; dicha autoridad se reserva el derecho de rechazarlo si no se ajusta a las presentes disposiciones. 
e) Ios correlatos sólo podrán ser presentados en las sesiones del Congreso por sus propios autores.

Agradcceremos que esa institución entere debidamente a sus correlatores de las nomas precedentes y también el pronto envío de la nómina de los mismos. Las Sociedades a las cuales pertenezcan los Relatores Oficiales, no deben designar correlatores sobre los mismos temas que aquéllos desarrollen.

Finalmente, adjuntamos el texto definitivo de los Estatutos de la Federación Latinoamericana de Sociedades de Obstetricia y Ginecología que fue apro. bado en el Primer Congreso Latinoamericano, el 29 de octubre de 1952. Saluda a usted muy atentamente.

Por la Secretaría Permanente de la FLASOG,

J. Alberto Castro. 